\title{
Urate Production by Human Heart
}

\section{Tom Huizer, ${ }^{*}$ Jan Willem de Jong, ${ }^{*}$ J. Arly Nelson, † Wlodzimierz Czarnecki, $†$ Patrick W. Serruys, ${ }^{*}$ Johannes J. R. M. Bonnier, $\S$ and Roel Troquay $\S$}

\author{
*Thoraxcenter, Erasmus University Rotterdam, The Netherlands; $\dagger$ Department of Experimental \\ Pediatrics, University of Texas M.D. Anderson Hospital and Tumor Institute, Ilouston, Texas, USA; \\ $\ddagger$ Department of Medicine and Medical Physiology, Faculty of Medicine, University of Calgary, \\ Calgary, Alberta, Canada; $§$ Department of Cardiology, Catharina Hospital, Eindhoven, The Netherlands
}

(Received 13 September 1988, accepted in revised form 3 March 1989)

\begin{abstract}
T. Huizer, J. W. de Jong, J. A. Nelson, W. Czarnecki, P. W. Serruys, J. J. R. M. Bonnier and R. Troqua Urate Production by Human Heart. Journal of Molecular and Cellular Cardiology (1989) 21, 691-695. Xanthine oxidoreductase has been demonstrated in the heart of various species. However, its presence in human heart is still debated. In the literature, high to undetectable levels have been reported. We studied the arterial-venous urate difference across the heart of patients undergoing both routine cardiac catheterization and percutaneous transluminal coronary angioplasty. Urate is the end product of the reaction catalysed by xanthine oxidoreductase. In 10 patients, studied before angioplasty, the plasma urate level in the great cardiac vein exceeded the arterial one by $26 \pm 10 \mathrm{nmol} / \mathrm{ml}(P=0.028)$. In a further 13 patients, urate production was maximal immediately after the last of four consecutive occlusions $(23 \pm 8 \mathrm{nmol} / \mathrm{ml}, P=0.018)$ and concomitant with increased coronary sinus hypoxanthine levels. We conclude that xanthine oxidoreductase is probably present in the heart of patients, suffering from ischemic heart disease, and responsible for the increase in urate production during transient myocardial ischemia.
\end{abstract}

Key Woros: Xanthine oxidase; Uric acid; Myocardium; Ischemia ; Human; Coronary angioplasty.

\section{Introduction}

Xanthine oxidoreductase activity has been demonstrated in the nyocardium of a number of species (see Schoutsen and De Jong, 1987). Limited data are available on the enzyme in human heart. Autopsy material indicates high xanthine oxidase activity (Krenitsky et al., 1974; Wajner and Harkness, 1988). Histochemical techniques have shown large amounts of the enzyme in human heart endothelium (Jarasch et al., 1986). On the other hand, several authors have reported very low to undetectable xanthine oxidoreductase activity in human heart (Ramboer, 1969; Eddy et al., 1987; Muxfeldt and Schaper, 1987). Preliminary observations assessing cardiac urate production in patients during pacing stress test at the University of Alabama (Nelson et al., 1977) and in patients during coronary angiography in the National Institute of Cardiology, Warsaw Czarnecki, 1988) have suggested that the human heart may be capable of urate production. We present evidence which shows that the human heart can produce significant amounts of urate. This observation suggests that a cardiac xanthine oxidoreductase is active in patients with ischemic heart disease.

\section{Methods}

\section{Patients}

Two studies were performed in patients, catheterized for percutaneous transluminal coronary angioplasty (PTC $\Lambda$ ). In 10 paticnts the urate concentrations of arterial and great cardiac vein plasma, obtained before PTCA, 
TABLE 1. Clinical characteristics of the study groups

\begin{tabular}{cccc}
\hline & Group 1 & & Group 2 \\
\cline { 2 - 2 } Variable & $n=10$ & & $n=13$ \\
\hline Age (year), average & 58 & & 58 \\
$\quad$ range & 49 to 66 & & 43 to 72 \\
$\begin{array}{c}\text { Gender (male/female) } \\
\text { CCS grade }\end{array}$ & $7 / 3$ & & $10 / 3$ \\
$\begin{array}{c}\text { Average severity } \\
\text { of stenosis (\%) }\end{array}$ & III to IV & II to IV \\
before PTCA & & \\
after PTCA & 78 & & 79 \\
\hline
\end{tabular}

CCS = Canadian Cardiovascular Society.

were assayed retrospectively (Group 1). Subsequently, in a prospective study (Group 2, 13 patients), urate and hypoxanthine concentrations were measured in arterial and coronary sinus plasma before, during and after angioplasty. In both studies, arterial blood was taken from the femoral artery. Great cardiac vein blood was sampled via the distal opening of a Wcbster flow cathcter (Group 1) and coronary sinus blood via a diagnostic catheter (Group 2). All patients had a proximal stenosis $<1 \mathrm{~cm}$ from the origin of the left anterior descending artery and no collateral filling to the region supplied by the artery, seen at angiography. Amipaque or Isopaque contrast agents (Nyegaard, Oslo, Norway) were used for angiography. In all patients, vasoactive substances, except short-lasting nitrates, were discontinued at least $12 \mathrm{~h}$ before the study. The clinical characteristics are listed in Table 1.

\section{Assays}

To prepare plasma, blood was mixed in a heparinized tube with an equal volume of icecold $154 \mathrm{~mm} \mathrm{NaCl}$, containing $20 \mu \mathrm{m}$ dipyridamole (Boehringer, Ingelheim, GFR) and $10 \mu_{\mathrm{M}}$ erythro-9-(2-hydroxy-3-nonyl)adenine (Wellcome, London, UK). These drugs were used to inhibit adenosine uptake and breakdown (Ontyd and Schrader, 1984; Edlund et al., 1985). The plasma was kept at $-80^{\circ} \mathrm{C}$. Deproteinization was carried out with an equal volume of $8 \% \mathrm{HClO}_{4}(\mathrm{w} / \mathrm{v})$ and the supernatant fraction neutralized with $2 \mathrm{M}$ $\mathrm{KOH} / 1 \mathrm{M} \mathrm{K}_{2} \mathrm{CO}_{3}$. HPLC-determination of urate and hypoxanthine concentrations in the plasma extract were performed on a $\mu$ Bondapak $\mathrm{C}_{18}$ column. A $100 \mu$ l sample was eluted with a mixture of $\mathrm{CH}_{3} \mathrm{OH}(100 \mathrm{ml})$ and $\mathrm{KH}_{2} \mathrm{PO}_{4}(10 \mathrm{~g} / 1,1000 \mathrm{ml}), \mathrm{pH} 5-7$, at a flow
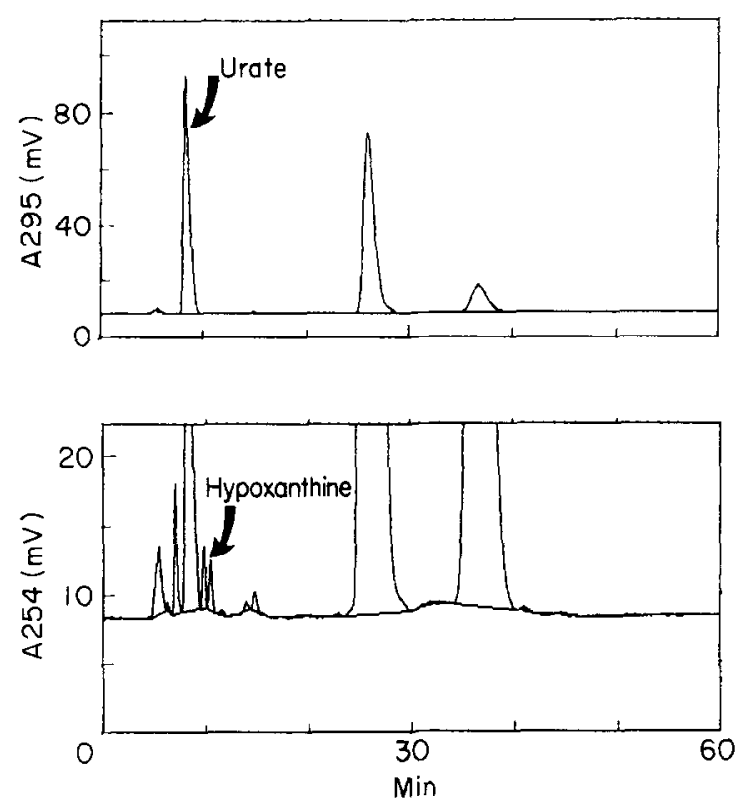

FIGURE 1. High-performance liquid chromatography of plasma extract. Urate was detected at 295 nm, hypoxanthine at $254 \mathrm{~nm}$. The contrast agent used showed up in the chromatogram, but did not interfere with the peaks of interest. 
TABLE 2. Arterial and venous urate levels before, immediately after four dilations, and during recovery

\begin{tabular}{|c|c|c|c|c|c|c|c|c|c|c|c|c|}
\hline \multirow{2}{*}{$\begin{array}{c}\text { Patient } \\
\text { no. }\end{array}$} & \multicolumn{2}{|c|}{ Before PTCA } & \multicolumn{2}{|c|}{ After lst dilation } & \multicolumn{2}{|c|}{ After 2nd dilation } & \multicolumn{2}{|c|}{ After 3rd dilation } & \multicolumn{2}{|c|}{ After 4th dilation } & \multicolumn{2}{|c|}{ Recovery } \\
\hline & ART & CS & ART & CS & ART & CS & ART & $\operatorname{CS}$ & ART & C.S & $A R T$ & CS \\
\hline 1 & 217 & 211 & 214 & 217 & 211 & 217 & 218 & 216 & 212 & 217 & 215 & 218 \\
\hline 2 & 236 & 216 & 224 & 184 & 216 & 195 & 213 & 207 & 213 & 200 & $20^{\circ}$ & 196 \\
\hline 3 & 224 & 229 & 223 & 220 & 218 & 215 & 218 & 219 & 217 & 217 & 215 & 211 \\
\hline 4 & 279 & 291 & 280 & 290 & 279 & 281 & 236 & 292 & 245 & 284 & $26^{c}$ & 282 \\
\hline 5 & 242 & 254 & 231 & 266 & 239 & 257 & 244 & 260 & 200 & 266 & 230 & 253 \\
\hline 6 & 216 & 224 & 219 & 221 & 208 & 216 & 211 & 218 & 209 & 216 & 202 & 206 \\
\hline 7 & 252 & 261 & 260 & 252 & 258 & 258 & 244 & 262 & 2.53 & 245 & $2+4$ & 240 \\
\hline 8 & 449 & 495 & 457 & 481 & 481 & 478 & 455 & 480 & 469 & $5 \mathrm{~L} 2$ & 462 & 469 \\
\hline 9 & 196 & 188 & 185 & 181 & 179 & 182 & 177 & 178 & 175 & 174 & 168 & 173 \\
\hline 10 & 230 & 242 & 218 & 214 & 201 & 207 & 197 & 209 & 191 & 204 & 187 & 197 \\
\hline 11 & 292 & 278 & 264 & 268 & 271 & 299 & 266 & 281 & 272 & 283 & 239 & 264 \\
\hline 12 & 239 & 207 & 241 & 191 & 234 & 224 & 220 & 230 & 184 & 238 & 225 & 221 \\
\hline 13 & 192 & 268 & 208 & 244 & 253 & 208 & 253 & 279 & 174 & 251 & 226 & 239 \\
\hline Mean & 251 & 259 & 248 & 248 & 250 & 249 & 242 & 256 & 232 & 254 & 237 & 244 \\
\hline S.E.M. & 18 & 21 & 19 & 22 & 21 & 21 & 19 & 21 & 21 & 23 & 20 & 21 \\
\hline
\end{tabular}

$A R T=$ arterial; $C S=$ coronary sinus. Data are in $\mathrm{nmol} / \mathrm{ml}$

rate of $0.6 \mathrm{ml} / \mathrm{min}$. The column was equipped with a LC-18 guard-column (Supelco, Bellefonte, PA). The Waters-HPLC equipment consisted of: WISP 710B cooled autosampler, Model 6000A pump, Model 490 multi wavelength detector, and Model 840 computer. Peaks were identified by retention times, internal standards and enzyme shifts. The optimal wavelengths for urate and hypoxanthine detection proved to be 295 and 254 $\mathrm{nm}$ as at these levels adsorption was maximal and disturbance by other materials minimal (Fig. 1). Sample preparation and assay were based on earlier work (Harmsen et al., 1981). In 27 arterial and venous plasma samples of Group 2, urate was also assayed spectrophotometrically with uricase according to Scheibe $e t$ al. (1974). Enzyme was provided by Boehringer (Mannheim, GFR). Comparison of the data obtained with both methods showed that they correlated closely.

Data presented were analysed with Student's $t$-test for paired variates, or, where appropriate with two-way analysis of variance. A $P$ value of $<0.05$ was considered as significant. The correlation test was done according to Bland and Altman (1986).

\section{Results}

In the preliminary studies, mentioned in the Introduction, hearts produced urate. In the
American study, the arterial and venous blood urate levels were $59 \pm 20$ and $120 \pm 23$ $\mathrm{nmol} / \mathrm{ml}$, resp. $(n=7, P=0.003)$. In the Polish study, these values were $96 \pm 15$ and $145 \pm 25 \mathrm{nmol} / \mathrm{ml}$ resp. $(n=6, P=0.028)$.

In Group 1, all patients had an isolated proximal left anterior descending artery stenosis and angina pectoris. In this group the arterial urate concentration was significantly lower than the coronary venous one $(216 \pm 17$ and $242 \pm 17 \mathrm{nmol} / \mathrm{ml})$; a difference of $26 \mathrm{nmol} / \mathrm{ml}(P=0.028)$. In seven out of 10 patients, the heart produced urate.

In a comparable patient population (Group 2, see Table 2), plasma urate concentrations were similar to those of Group 1, but the arterio-venous difference before coronary angioplasty was relatively small. Consequently we were unable to demonstrate significant urate production before coronary angioplasty. Analysis of data showed a significant increase. in urate production during balloon inflations $(\mathrm{F}=2.85 ; P<0.05)$. After the third and fourth inflations, venous urate levels were significantly higher than arterial ones (Fig. 2). They differed $14 \mathrm{nmol} / \mathrm{ml}(P=0.009)$ and 23 $\mathrm{nmol} / \mathrm{ml}(P=0.018)$, resp. Even after $15 \mathrm{~min}$ of recovery, urate production was still significant. The difference was $7 \mathrm{nmol} / \mathrm{ml}$ $(P=0.033)$.

In the latter study we also measured the arterial and coronary sinus hypoxanthine levels with HPLC. The arterial hypoxanthine 


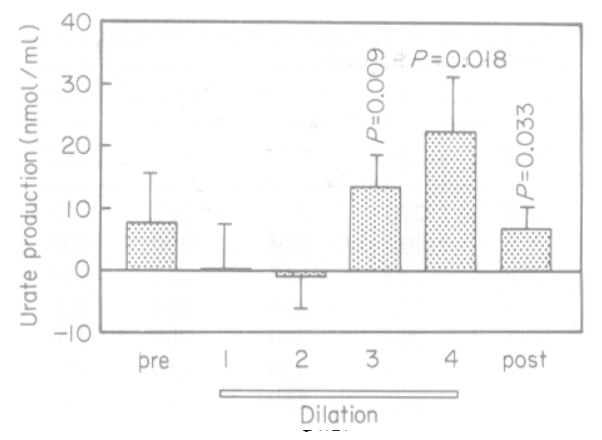

FIGURE 2. Urate production by the heart of 13 patients with single left anterior descending coronary artery stenosis, before coronary angioplasty (pre), after each balloon deflation (dilation one to four) and after 15 min of recovery (post). Mean coronary venous-arterial values are given with 1 s.E.M. Significant urate production was found immediately after the last two dilations, and during recovery.

plasma concentration slightly exceeded the venous one before angioplasty $(0.58 \pm 0.07$ and $0.42 \pm 0.07 \mathrm{nmol} / \mathrm{ml}$, respectively, $P=0.015)$. Immediately following PTCA these values were $0.32 \pm 0.06$ and $1.28 \pm 0.19$ $\mathrm{nmol} / \mathrm{ml}$, respectively, $P<0.001$ (average of four attempts). Thus cardiac uptake turned into production. Fifteen minutes after angioplasty arterial plasma hypoxanthine levels were not different from the venous ones.

\section{Discussion}

Xanthine oxidoreductase activity is detectable in the heart of a number of species (for reviews, see Schoutsen and De Jong, 1987; Downey et al., 1988). In pig heart it seems to be absent (Podzuweit et al., 1986; Muxfeldt and Schaper, 1987). In rabbit heart both Schoutsen et al. (1983) and Chambers et al. (1985) were unable to demonstrate the enzyme, but Wajner and Harness (1988) measured high activity. The literature on xanthine oxidoreductase in human heart is also conflicting. The reports vary from high (Krenitsky et al., 1974; Jarasch et al., 1986; Wajner and Harness, 1988) to (very) low levels (Watts et al., 1965; Ramboer, 1969; Eddy et al., 1987; Muxfeldt and Schaper, 1987). We want to emphasize that in these reports the number of samples assayed was often very small. Muxfeldt and Schaper (1987) found very low amounts of xanthine oxidoreductase in the two human heart biopsies studied. Krenitsky et al. (1974) reported data on one autopsy sample. These authors observed enzyme activity with ferricyanide as the electron acceptor but did not use NAD or oxygen as the cosubstrate. Allopurinol inhibited the activity. Eddy et al. (1987) could not demonstrate xanthine oxidoreductase in human ventricular tissue. Supposedly the four biopsies studied were not taken from ischemic hearts.

A possible explanation for the discrepancies in activity found could be a difference in quality of the hearts examined. Our data indicate that the enzyme could be active in the human heart in vivo. We cannot exclude that the urate production measured originated from xanthine oxidoreductase activity in polymorphonuclear neutrophils, adhering to areas of the coronary endothelium that are injured by the balloon during inflation.

In the American and Polish studies, mentioned before, blood was deproteinized with $\mathrm{HClO}_{4}$ which causes a partial loss during sample clean-up. Never the less the arteriovenous differences in urate were significant. Moreover, they suggested that patients with a more severe ischemic heart disease produced the highest amounts of urate. In the American study, patients experiencing pain during a pacing stress test released lactate and showed the highest urate production. Czarnecki (1988) observed that patients with a history of subendocardial infarction produced high amounts of urate whereas patients with normal myocardium or extensive myocardial damage produced less. Our present results support this idea. Group 1, which comprised patients with CCS grades III and IV, showed significant urate production before PTCA. Group 2, in which four out of 13 patients were CCS grade II, only started to produce significant amounts of urate after several dilations. After each of the angioplasty attempts, venous plasma hypoxanthine [the relatively stable substrate for xanthine oxidoreductase (Harkness, 1988)] increased fourfold. The data suggest that ischemic myocardium at risk of infarction produces urate.

Patients of Group 1, all with a proximal stenosis of the left anterior descending coronary artery produced urate (Table 1 ). It is likely that this urate production was partly 
due to endothelial damage, caused by insertion of the guide wire and the balloon catheter. In Group 2 urate production, which was not significant before PTCA, became obvious after repetitive angioplasty attempts (Fig. 2). Presumably, this is due to cardiac ATP breakdown, with a concomitant rise in hypoxanthine as a result of myocardial ischemia due to coronary occlusion by balloon inflation (see also Serruys et al., 1989). Hypoxanthine serves as a substrate for xanthinc oxidoreduc- tase. We suggest that the human heart may contain active xanthine oxidoreductase.

\section{Acknowledgements}

The authors greatly appreciate the technical assistance of Petra Noomen and Heleen van Loon, the helpful comments of Kevin Beatt, and the secretarial assistance of Ria KantersStam. The nursing staff of the hospitals concerned gave valuable support.

\section{References}

Bland JM, Altman DG (1986) Statistical methods for assessing the agreement between two methods of clinical measurement. Lancet i : 307-310.

Cihambers DE, Pakks DA, Patterson G, Roy R, McCord JM, Yoshida S, Parmley LF, Downey JM 1985: Xanthine oxidase as a source of free radical damage in myocardial ischemia. J Mol Cell Cardiol 17: 141-152.

Czarneck W (1988) Apparent inosine incorporation and concomitant haemodynamic improvement in human heart. In: Myocardial Energy Metabolism, edited by JW de Jong, Dordrecht, Martinus Nijhoff, pp. 257-264.

Downey JM, Hearse DJ, Yellon DM (1988) The role of xanthine oxidase during myocardial ischemia in several species including man. J Mol Cell Cardiol 20, (Suppl. 2) : 55-63.

Eddy LJ, Stewart JR, Jones HP, Engerson TD, McCord JM, Downey JM (1987) Free radical-producing enzyme, xanthine oxidase, is undetectable in human hearts. Am J Physiol 253: H709-H711.

Edlind A., Berglund B, van Dorne D, Kaijser L, Nowak J, Patrono C, Sollevi A, Wennmalm Å (1985) Coronary flow regulation in patients with ischemic heart disease: release of purines and prostacyclin and the effect of inhibitors of prostaglandin formation. Circulation $71: 1113-1120$.

HaRkness RA (1988) Hypoxanthine, xanthine and uridine in body fluids, indicators of ATP depletion. J Cihromatogr 429 : 255278.

Harmsen E, de Jong JW, Serruys PW (1981) Hypoxanthine production by ischemic heart demonstrated by high pressure liquid chromatography of blood purine nucleosides and oxypurines. Clin Chim Acta $115: 73-84$.

Jarasch ED, Bruder G, Heid HW (1986) Significance of xanthine oxidase in capillary endothelial cells. Acta Physiol Scand 548, (Suppl.) : 39-46.

Krenitsky TA, Tuttle JV, Cattau EL, Wang P (1974) A comparison of the distribution and electron acceptor specificities of xanthine oxidase and aldehyde oxidase. Comp Biochem Physiol 49B : 687-703.

Muxfeld M, Schaper W (1987) The activity of xanthine oxidase in hearts of pigs, guinea pigs, rats, and humans. Basic Res Cardiol 82 : 486-492.

Nelson JA, McDaniel HG, Maurer BJ, Hill WA, James TN (1977) Apparent uptake of purines by the human heart. N Eng J Med 296: 115 (Letter to the Ed).

Ontyd J, Schrader J (1984) Measurement of adenosine, inosine and hypoxanthine in human plasma. J Chromatogr 307: 404 409 .

Podzuweit T, Braun W, Müller A, Schaper W (1986) Arrhythmias and infarction in the ischemic pig heart are not mediated by xanthine oxidase-derived free oxygen radicals. Circulation 74, (Suppl. 2): 346 (Abstract).

Ramboer CRH (1969) A sensitive and nonradioactive assay for serum and tissue xanthine oxidase. J Lab Clin Med 74 828-835.

Scheibe B, Bernt E, Bergmeyer H-U (1974) Uric acid. In: Methods of Enzymatic Analysis, edited by H-L Bergmeyer New York, Academic Press, pp. 1951-1958.

SGHOUtsen B, DE Jong JW (1987) Agc-depcndent increase in xanthine oxidoreductase differs in various heart cell types. Circ Res 61 : 604-607.

Schoutsen B, de Jong JW, Harmsen E, de Tombe PP, Achterberg PW (1983) Myocardial xanthine oxidase/ dehydrogenase. Biochim Biophys Acta 762: 519-524.

Serruys PW, Suryapranata H, Piscione F, Harmsen E, van den Brand M, de Feyter P, Hugenholtz PG, de Jong JW (1989) Myocardial release of hypoxanthine and lactate during percutaneous transluminal coronary angioplasty. Am J Cardiol 63: 45E-51E.

Wajner M, Harkness RA (1988) Distribution of xanthine dehydrogenase and oxidase activities in human and rabbit tissues. Biochem Soc Trans 16: 358-359.

Watts RWE, Watts JEM, Seegmiller JE (1965) Xanthine oxidase activity in human tissues and its inhibition by allopurinol (4-hydroxypyrazolo[3,4-d]pyrimidine). J Lab Clin Med 66: 688-697. 